\title{
Effects of Micropit Depths on Tribology Performance of Textured Port Plate Pair
}

\author{
Haishun Deng $\mathbb{D D}^{1,2}$ Shiju He, ${ }^{1}$ Feiyu Mao, ${ }^{1}$ and Chuanli Wang ${ }^{1}$ \\ ${ }^{1}$ School of Mechanical Engineering, Anhui University of Science and Technology, Huainan, Anhui 232001, PR, China \\ ${ }^{2}$ The State Key Laboratory of Fluid Power and Mechatronic Systems, Zhejiang University, Hangzhou 310027, PR, China \\ Correspondence should be addressed to Haishun Deng; dhs1998@163.com
}

Received 17 August 2018; Accepted 22 October 2018; Published 11 November 2018

Academic Editor: Alicia E. Ares

Copyright (C) 2018 Haishun Deng et al. This is an open access article distributed under the Creative Commons Attribution License, which permits unrestricted use, distribution, and reproduction in any medium, provided the original work is properly cited.

\begin{abstract}
In order to improve the friction and wear performance of textured port plate pair, effects of the micropit depth on the tribology performance is studied in the paper. The relation between the micropit depth and the port plate pair's oil loading carrying capacity is analyzed in theory; with the friction coefficient, the wear volume and the surface roughness as the evaluation criteria, effects of the micropits' depth on the tribology performance are investigated. The conclusions are shown as follows: oil loading capacity would come to its peak when the oil film thickness is equal to the micropit depth; the optimal micropit depth is unrelated to the area ratios and micropits' diameters. With the same parameters, the effects of antifriction is optimal when the micropits' depth is $10 \mu \mathrm{m}$, while antiwear and surface integrity are optimal when $15 \mu \mathrm{m}$. When the micropits' depth is $5 \mu \mathrm{m}$, the antiwear, surface roughness, and antifriction are worse compared with those of the untextured port plate pair.
\end{abstract}

\section{Introduction}

The port plate pair is an important friction pair of the axial piston pump/motor, and friction and wear are the leading causes of its failure; for this reason, the port plate pair's tribology performance is a research hotspot $[1,2]$. The common measures to improve the port plate pair's surface tribology performance are as follows: improving surface treatment processes [3], coating [4-6] and improving lubrication property through changing the port plate pair's structure [7-11], and so on.

These measures improve the surface and lubrication properties to a certain extent, which would largely result in the improvement of the work performance and the service life of the axial piston pump.

According to the work principle and the structure features of the axial piston pump's port plate pair, texturing the components of the port plate pair is also an effective measure to improve its friction and lubrication feature [12-14]. The surface texture parameters, especially the micropit depth, have a considerable effect on the tribology performance of the port plate pair [15-17], therefore, through theoretical analysis and experimental verification, the effect of the micropit depth on the textured port plate pair is discussed in this paper.

\section{The Effect of the Micropit Depth on the Oil Film Loading Carrying Capacity}

Because the textured friction pairs can produce the additional oil film loading carrying capacity and texturing the port plate in the low pressure area would improve the mechanical property and the tribology performance, as is shown in Figure 1, the textured port plate pair discussed in this paper mainly refers to that in low pressure area. The structural sizes of the port plate are shown as follows: the inside belt's radii $r 1$ and $r 2$ of the port plate are $17 \mathrm{~mm}$ and $19 \mathrm{~mm}$, respectively, and the outside belt's radii $r 3$ and $r 4$ of the port plate are $23 \mathrm{~mm}$ and $27.5 \mathrm{~mm}$, respectively. In order to provide the theoretical basis for the study on the micropit depth's effect on the textured port plate's tribology performance, the effect of the micropit depth on the oil film 


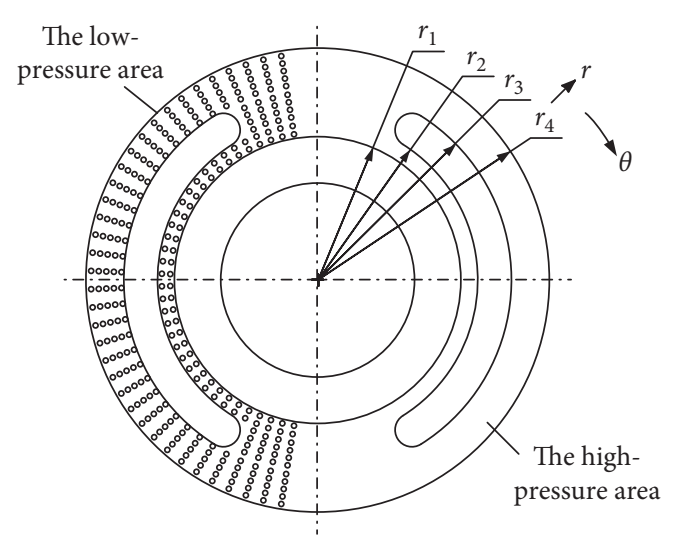

Figure 1: Textured port plate pair.

loading carrying capacity should be studied by the numerical computation, which can be referred to in the related literature $[18,19]$.

Figure 2 shows that the dimensionless loading carrying capacity changes with the micropits' depths at different textured parameters. In Figure 2(a), when the area ratio is $10 \%$ and the oil film thickness is $10 \mu \mathrm{m}$, the dimensionless loading carrying capacity at the four micropit diameters $(100 \mu \mathrm{m}, 200 \mu \mathrm{m}, 300 \mu \mathrm{m}$, and $400 \mu \mathrm{m})$ would be the maximal loading carrying capacity if the micropit is $10 \mu \mathrm{m}$ deep. Figure 2(b) indicates the relationship between the dimensionless loading carrying capacity and the micropit depth at different area ratios when the micropit is $300 \mu \mathrm{m}$ in diameter and the oil film is $10 \mu \mathrm{m}$ thick, which shows that loading carrying capacity is maximal when the micropit is $10 \mu \mathrm{m}$ deep. Figure 2(c) shows the relationship between the dimensionless loading carrying capacity and the micropit depth at different oil film thicknesses when the area ratio is $10 \%$ and the micropit diameter is $400 \mu \mathrm{m}$, which displays that with the oil film thicknesses $5 \mu \mathrm{m}, 10 \mu \mathrm{m}, 15 \mu \mathrm{m}, 20 \mu \mathrm{m}$, and $25 \mu \mathrm{m}$ and micropit depth $5 \mu \mathrm{m}, 10 \mu \mathrm{m}, 15 \mu \mathrm{m}, 20 \mu \mathrm{m}$, and $25 \mu \mathrm{m}$, respectively, there would appear the maximum loading carrying capacity.

It can be concluded that when the oil film thickness is equal to the micropit depth, the textured port plate pair has the maximum loading carrying capacity; when the oil film thickness is bigger than the micropit depth, the oil film loading carrying capacity decreases with the increase in the micropit depth; and when the oil film thickness is smaller than the micropit depth, the oil film loading carrying capacity decreases with the decrease in the micropit depth. Moreover, the optimal micropit depth is practically not related to the micropit diameter and the area ratio.

\section{The Effect of the Micropit Depth on the Tribology Performance}

The experiment was conducted with a self-made test machine in unidirectional orbiting, as is shown in Figure 3. The textured parameters of the port plate are shown in Table 1. With the friction coefficient, the wear volume, and the surface roughness as the evaluation criteria, effects of the micropit depth on the tribology performance are further investigated.

3.1. The Friction Coefficient. Figures 4-6 show that the friction coefficient and the antifriction ratio change with the micropit depths under the condition of three area ratios and four rotate speeds when the micropit is $100 \mu \mathrm{m}$ in diameter and the loading force $1000 \mathrm{~N}$.

In Figure 4(a), the area ratio is $10 \%$, the micropits are $5 \mu \mathrm{m}$ deep, and the friction coefficients seem a bit closer and are larger than the others at different rotate speeds. When the rotate speeds are $600 \mathrm{r} / \mathrm{min}$ and $750 \mathrm{r} / \mathrm{min}$ and the micropits' depth is $10 \mu \mathrm{m}$, the textured port plate pair has an optimal antifriction effect; when the rotate speeds are $300 \mathrm{r} / \mathrm{min}$ and $450 \mathrm{r} / \mathrm{min}$ and the micropits are $15 \mu \mathrm{m}$ deep, the textured port plate pair has an optimal antifriction effect. As is shown in Figure 4(b), under the conditions of the abovementioned 3 micropit depths and 4 different rotate speeds, antifriction effect does exist to some extent in the textured port plate pair. As a whole, the antifriction ratio at the depth of $10 \mu \mathrm{m}$ is close to that at the depth of $15 \mu \mathrm{m}$, with the maximal antifriction ratio $32.61 \%$, corresponding micropit depth $15 \mu \mathrm{m}$, and the rotate speed $300 \mathrm{r} / \mathrm{min}$.

From Figure 3(a), it can be seen that, with the area ratio $10 \%$, the friction coefficients are close to each other and antifriction effect would be the poorest at different rotate speeds when the micropits are $5 \mu \mathrm{m}$ deep. When the micropits' depth is $10 \mu \mathrm{m}$, the antifriction effect would be the best and the antifriction ratio is closest to that at the depth of $15 \mu \mathrm{m}$, with the maximum difference only $13.21 \%$. The antifriction shown in Figure 3(b) indicates that the textured port plate pairs at the 4 rotate speeds all have negative antifriction ratios, giving expression to an increasing effect on friction. When the micropits' depths are $10 \mu \mathrm{m}$ and $15 \mu \mathrm{m}$, the difference between the two corresponding antifriction ratios is very small. When the micropits' depth is $10 \mu \mathrm{m}$ and the rotate speed is $300 \mathrm{r} / \mathrm{min}$, the maximum antifriction ratio is $27.98 \%$.

In Figure 6, it can be seen that, with the area ratio $20 \%$, the textured port plate pair has the worst antifriction effect at different rotate speeds when the micropits are $5 \mu \mathrm{m}$ deep, while it has the best antifriction effect when the micropits are $10 \mu \mathrm{m}$ deep. The friction coefficients at the three rotate speeds (except for the speed of $300 \mathrm{r} / \mathrm{min}$ ) and at the three micropit depths are very close to each other.

In conclusion, when the parameters such as the loading force, the rotate speed, and other textured parameters remain the same, the textured port plate pair has the best antifriction effect when the micropits are $10 \mu \mathrm{m}$ deep, while it has worst antifriction effect when the micropits are $5 \mu \mathrm{m}$ deep.

3.2. The Wear Volume. The time of the wear experiment is 10 hours; the wear volume of the upper test specimen is measured as the evaluation parameter. The results are analyzed as follows.

Figure 7 (a) shows that the wear volume changes with the micropit depths when the micropit diameter is $100 \mu \mathrm{m}$ and 


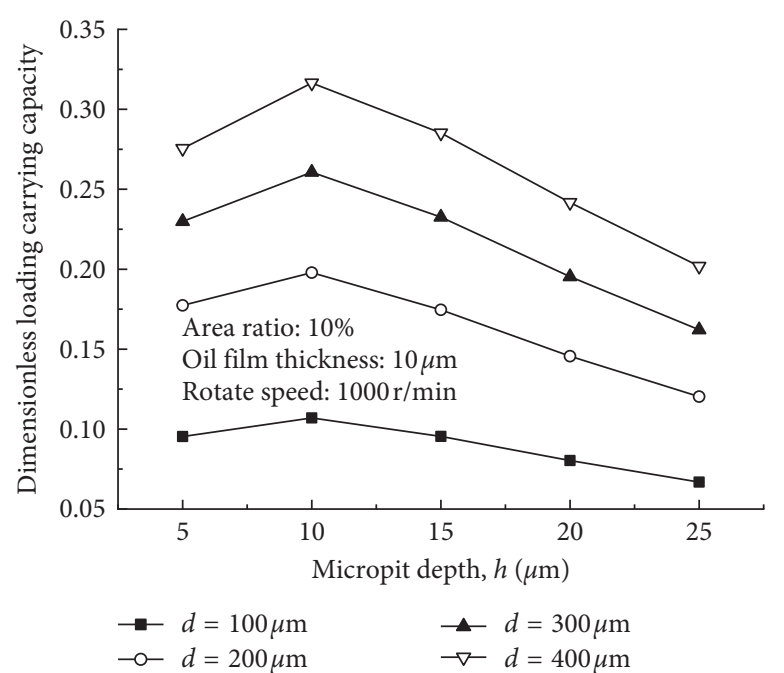

(a)

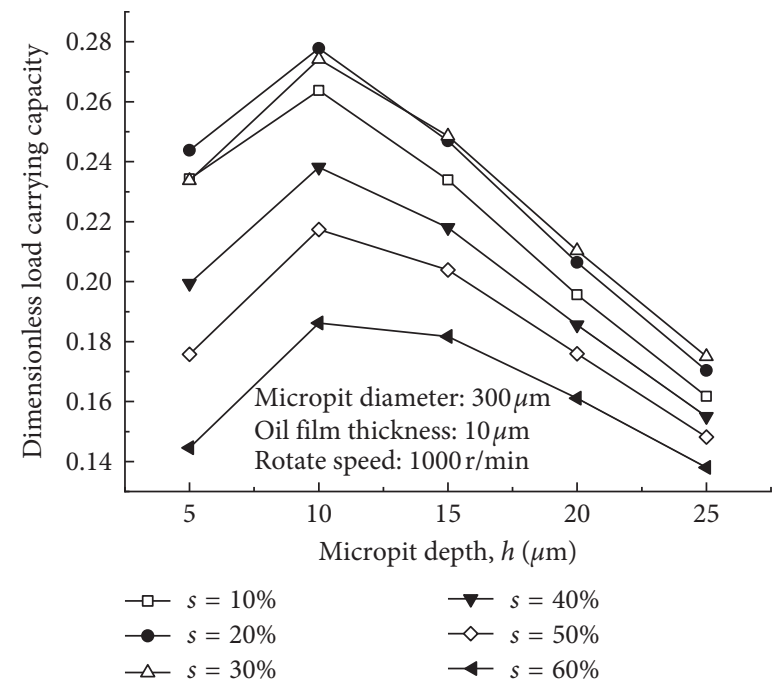

(b)

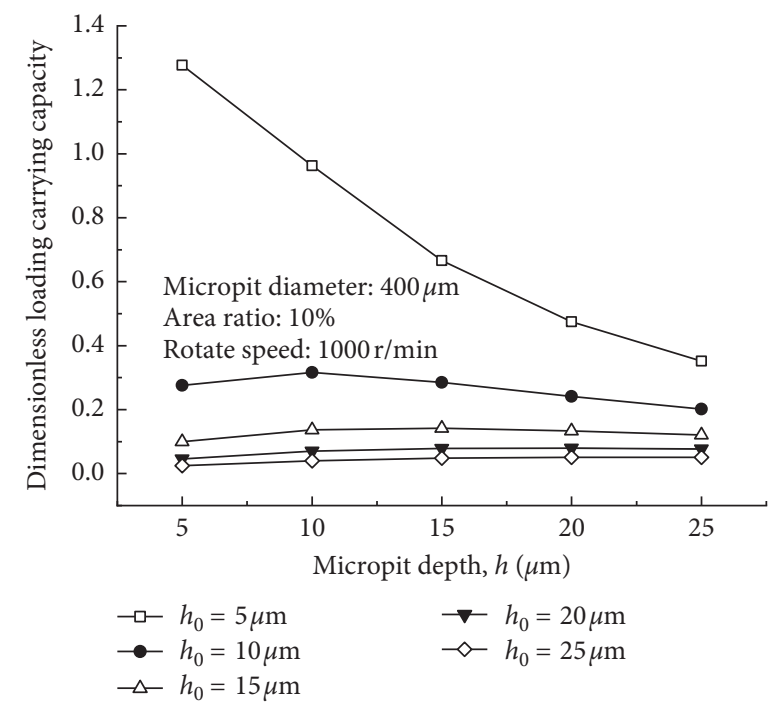

(c)

Figure 2: Relation between dimensionless pressure and micropits' depth. (a) The different micropit diameter. (b) The different micropit depth. (c) The different oil film thickness.

the area ratios are $5 \%, 10 \%, 15 \%$, and $20 \%$. Overall, the decreased wear volumes four area ratios are rather small, but they are the smallest when the micropits are $10 \mu \mathrm{m}$ deep, with the wear volume at the depth of $15 \mu \mathrm{m}$ the second place and that at the depth of $5 \mu \mathrm{m}$ the third place. With the same micropits' depth, the antiwear effect is optimal when the area ratio is $10 \%$. The optimal antiwear ratio could amount to $88.65 \%$ when the micropits are $10 \mu \mathrm{m}$ deep and the area ratio is $10 \%$.

Compared with the untextured port plate pair, the textured port plate pair displays greater effect on antifriction when the area ratio is $15 \%$ and the micropits' depths are $5 \mu \mathrm{m}$ and $15 \mu \mathrm{m}$, respectively. To put it more accurately, the wear volume of the textured port plate pair increases over 10 times when the area ratio is $15 \%$ and the micropits' depth is $5 \mu \mathrm{m}$.
Figure 7(b) shows that the wear volume changes with the micropits' depths when the micropit's diameter is $300 \mu \mathrm{m}$ and the area ratios are 5\%,10\%,15\%, and $20 \%$. Different from Figure 7(a), antiwear effect comes to its best when the micropit depth is $15 \mu \mathrm{m}$; the effect at the depth of $10 \mu \mathrm{m}$ comes the second, similar to that at the depth of $15 \mu \mathrm{m}$; the effect at the depth of $5 \mu \mathrm{m}$ is the worst. With the same micropit depth, the antifriction effect is relatively obvious when the area ratios are $10 \%$ and $15 \%$, but it is not so ideal when $5 \%$ and $20 \%$. The smallest antiwear effect occurs when the area ratio is $15 \%$ and the micropits' depth is $15 \mu \mathrm{m}$, with antiwear ratio $92.42 \%$ compared to that of the untextured port plate pair. Both the wear volumes increase in the cases of the $5 \%$ area ratio and the $5 \mu \mathrm{m}$ deep micropits and the $20 \%$ area ratio and the $10 \mu \mathrm{m}$ deep micropits, with the increase in the wear ratios $29.08 \%$ and $303.16 \%$, respectively. 


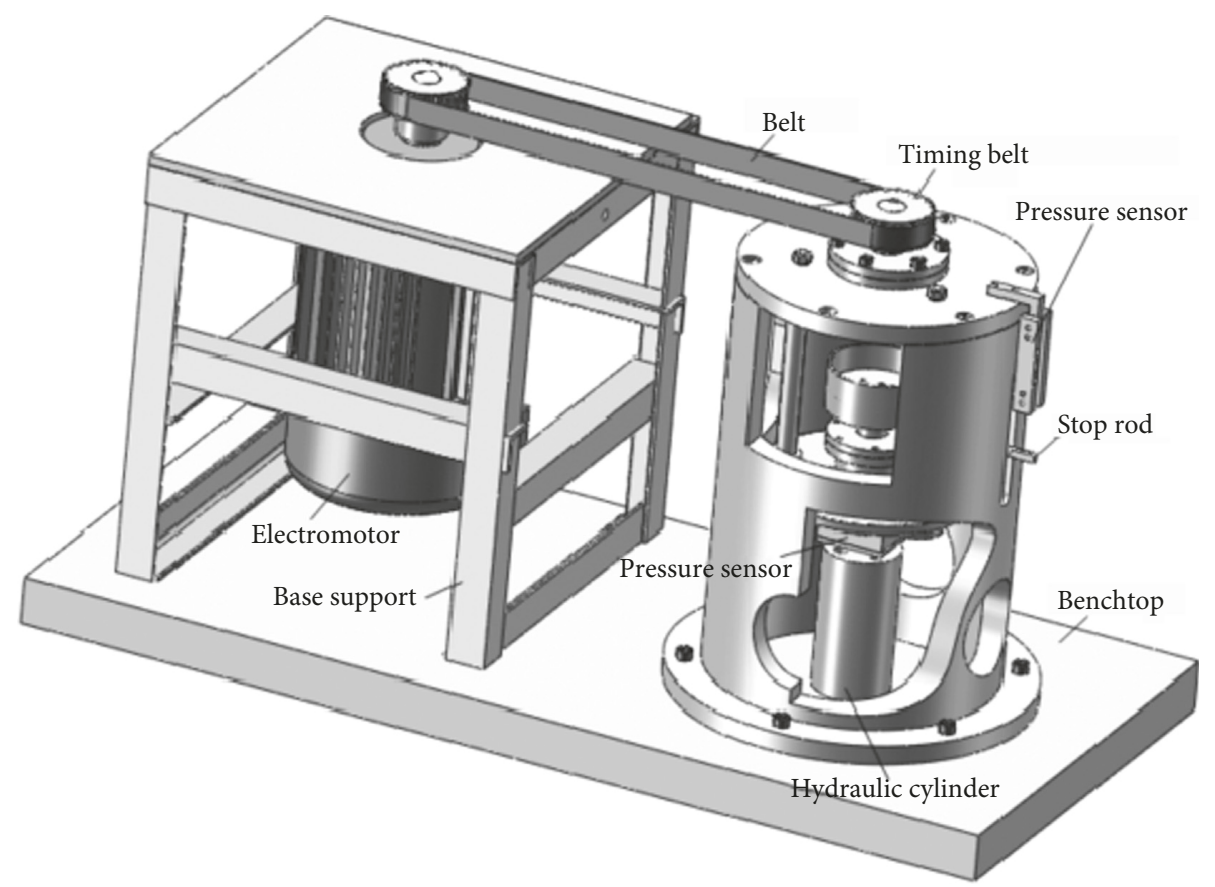

FIGURE 3: The self-made test machine.

TABLE 1: The textured parameters of the port plate.

\begin{tabular}{lcc}
\hline Diameter, $d(\mu \mathrm{m})$ & Depth, $c(\mu \mathrm{m})$ & Area ratio, $s(\%)$ \\
\hline 50 & $5-15$ & $5 \sim 20$ \\
100 & $5-15$ & $5 \sim 20$ \\
200 & $5-15$ & $5 \sim 20$ \\
300 & $5-15$ & $5 \sim 20$ \\
\hline
\end{tabular}

3.3. The Surface Roughness. In order to investigate the wear of the textured port plate pair, the surface roughness of the upper test specimen is measured.

Figure $8(a)$ shows that the surface roughness changes with the micropit depths when the micropit diameter is $100 \mu \mathrm{m}$ and the area ratios are $5 \%, 10 \%, 15 \%$, and $20 \%$, whose histogram is similar to that of the corresponding wear volume. At different area ratios, the surface roughness at the micropit depth of $5 \mu \mathrm{m}$ is the largest, that at the depth of $15 \mu \mathrm{m}$ comes the second, and that at the micropit depth of $10 \mu \mathrm{m}$ is the smallest. Under the circumstances of the three micropits' depths, all the surface roughnesses are the smallest when the area ratio is $10 \%$. The minimum surface roughness occurs when the area ratio is $10 \%$ and the micropit depth is $10 \mu \mathrm{m}$, while the maximum surface roughness appears when the area ratio is $15 \%$ and the micropit depth is $5 \mu \mathrm{m}$.

In Figure 8(b), the histogram shows that the surface roughness changes with the micropit depth when the micropit diameter is $300 \mu \mathrm{m}$ and the area ratios are $5 \%, 10 \%$, $15 \%$, and $20 \%$. When the micropit depth is $15 \mu \mathrm{m}$, the surface roughnesses under the circumstances of different area ratios are the smallest, indicating that the textured port plate pair has the least chance to contact the wear solid at such a micropit depth. When micropits are $10 \mu \mathrm{m}$ deep, the surface roughnesses rank the second smallest, very close to that at the micropit depth of $15 \mu \mathrm{m}$. When the micropits are $5 \mu \mathrm{m}$ deep, the surface roughnesses come at the third place. The smallest surface roughness of the textured port plate pair appears when the area ratio is $15 \%$ and the micropit depth is $15 \mu \mathrm{m}$.

As can be seen in Figure 8, the effect of the micropit depth on the wear volume bears the resemblance to that on the surface volume; that is, the smaller micropit depth is not conducive to keep the surface topography of the textured port plate pair.

\section{Discussions}

According to the theoretical analysis, with the same other textured parameters, the textured port plate pair would produce the maximum loading carrying capacity (hydrodynamic pressure) when the micropit depth is equal to the oil film thickness. The oil film thickness is ordinarily about $10 \mu \mathrm{m}$ when the axial piston pump works. When the micropit depth is $10 \mu \mathrm{m}$, the loading carrying capacity can limit the direct contact between the port plate and the cylinder to the greatest degree. As a result, the friction coefficient is smaller while the antiwear ratio is higher. Meanwhile, the antifriction effect would be lowered if the micropit depth is too big and restrained by the surface tension of the hydraulic oil.

For the untextured friction pair, the change of the friction coefficient reflects its lubricating state. The wear of the friction pair depends on the nature of the materials on one hand and the lubricating state on the other hand when the friction pair's materials are of no significant difference, a one-to-one correspondence between the wear volume and the friction coefficient. Uniformly distributed micropits can accommodate a number of solid particulates, so the change 


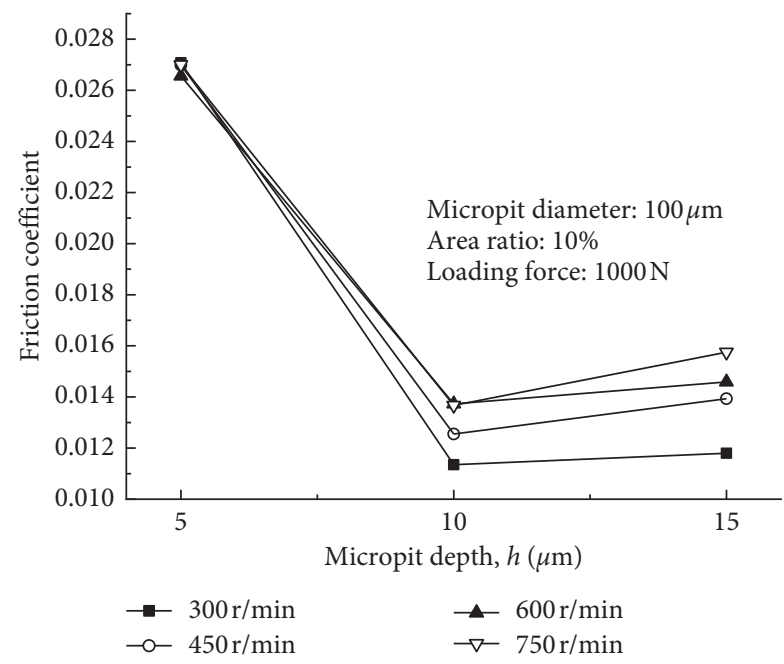

(a)

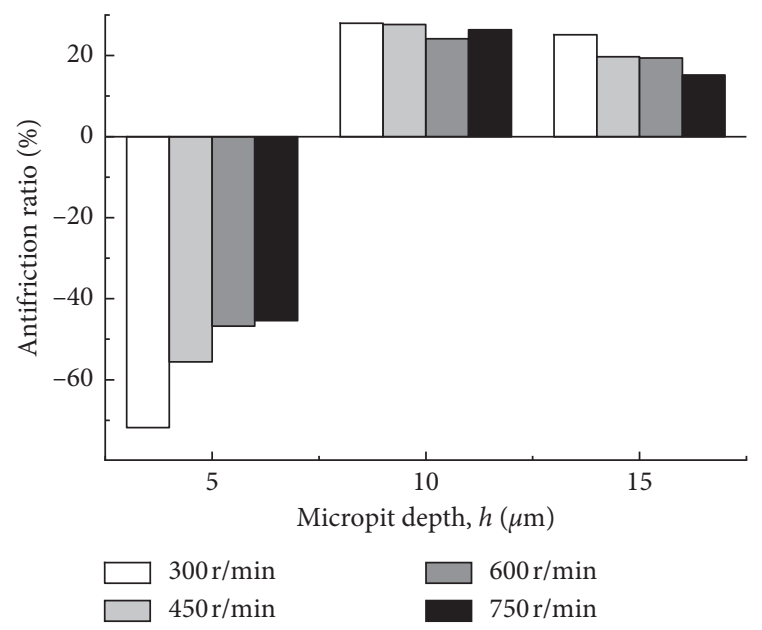

(b)

Figure 4: (a) Friction coefficient and (b) antifriction ratio when the value of the area ratio is $10 \%$.

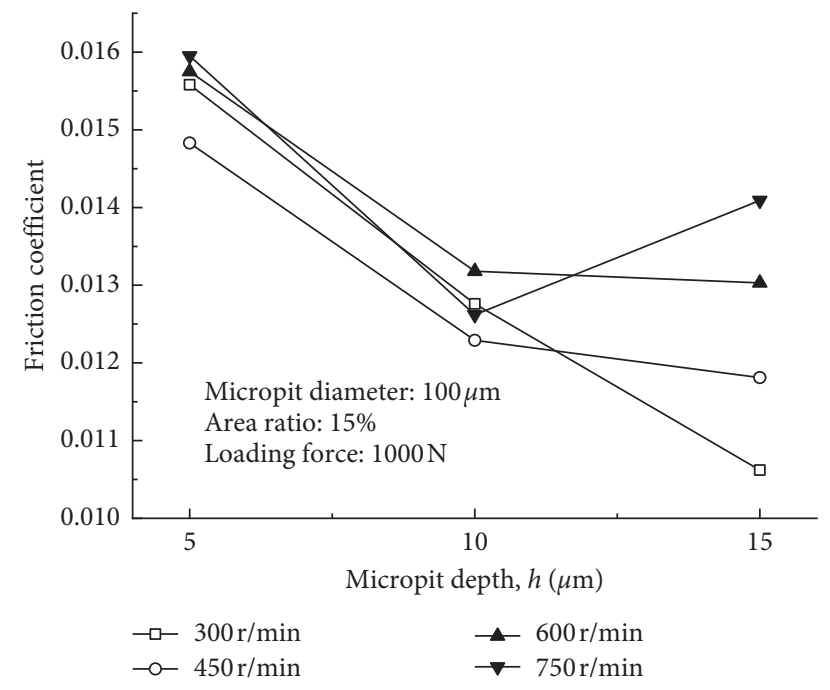

(a)

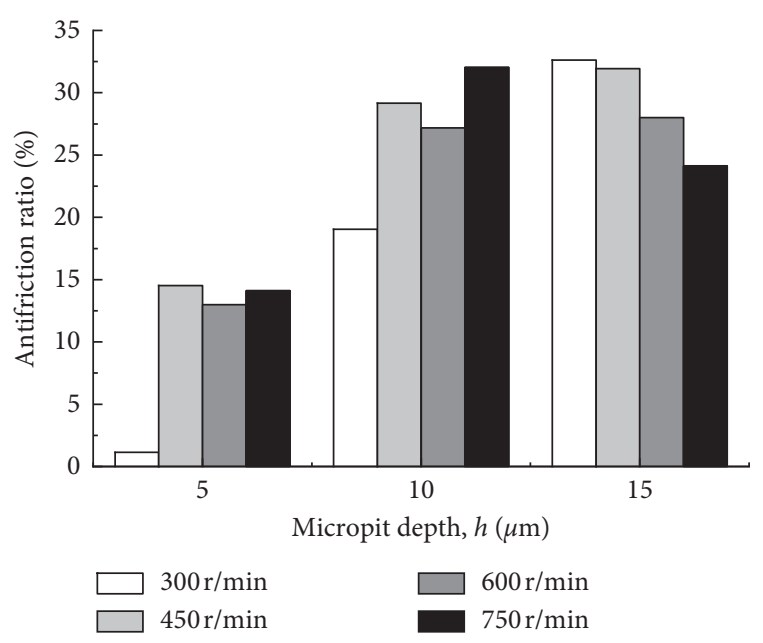

(b)

FIgURE 5: (a) Friction coefficient and (b) antifriction ratio when the value of the area ratio is $15 \%$.

laws of the wear volume are naturally different from those of the friction coefficient in the textured port plate pair.

When the micropit diameter is $300 \mu \mathrm{m}$, the friction coefficient is minimum at the micropit depth of $10 \mu \mathrm{m}$ while the wear volume minimum at the micropit depth of $15 \mu \mathrm{m}$, indicating the difference in the change laws between friction coefficient and wear volume. In the light of the case, the analysis can be carried out as follows: the solid particulates in the oil can be deposited more easily for the larger micropit diameter of $300 \mu \mathrm{m}$; as the more solid particulates are deposited in the micropits over time, the micropits will become shallow. As a result, the surface with the micropit depth of $5 \mu \mathrm{m}$ is close to the smooth surface and the micropits of $10 \mu \mathrm{m}$ become shallow too, which makes them to have the same tribology performance with that of the real $5 \mu \mathrm{m}$ deep micropits, displaying the maximum wear volume. Similarly, after the surface of the $15 \mu \mathrm{m}$ deep micropits deposits the solid particles and becomes shallower, the $15 \mu \mathrm{m}$ deep micropits have the best antiwear performance instead. It is worth noting that the antiwear effect will be limited with the excessive micropit depth due to the surface tension of the oil.

For the micropits with diameter $100 \mu \mathrm{m}$, the surface is not easy to deposit the solid particles; therefore, the change laws of the wear volume are consistent with those of the friction coefficient when the micropit depths are $5 \mu \mathrm{m}$, $10 \mu \mathrm{m}$, and $15 \mu \mathrm{m}$.

\section{Conclusion}

The effects of the micropit depth on the tribology performance of the textured port plate pair are explored in this paper, and the results are shown as follows: 


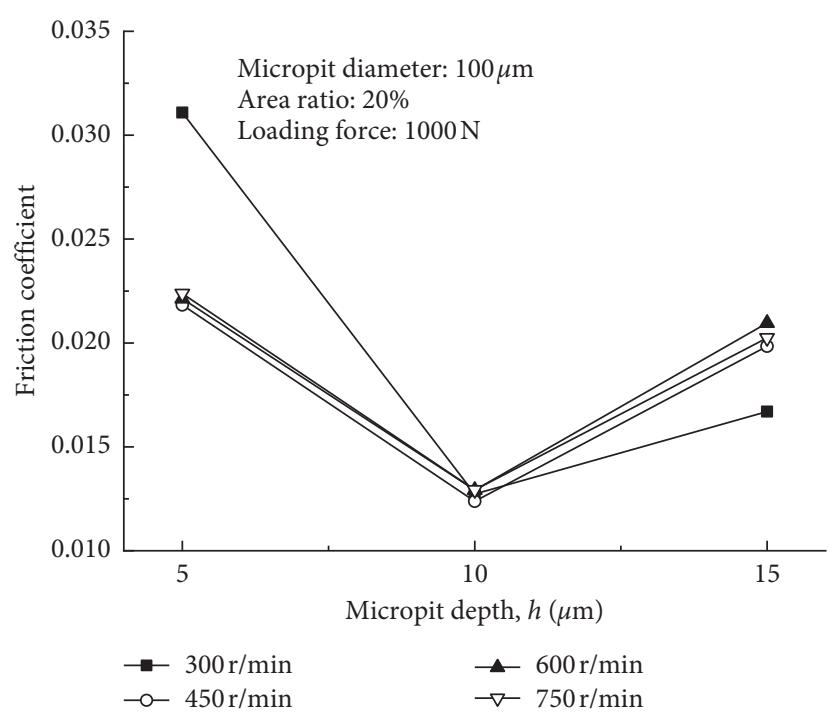

Figure 6: Friction coefficient when the value of the area ratio is $20 \%$.

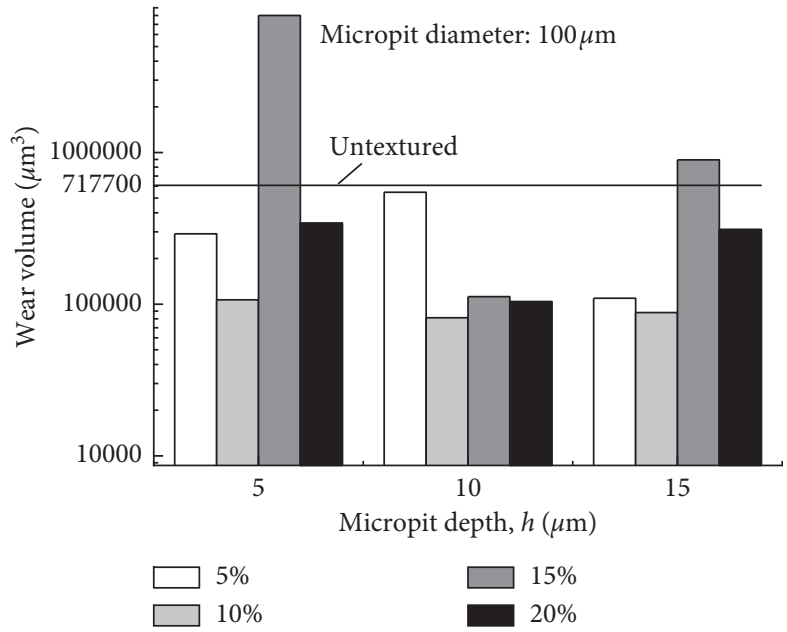

(a)

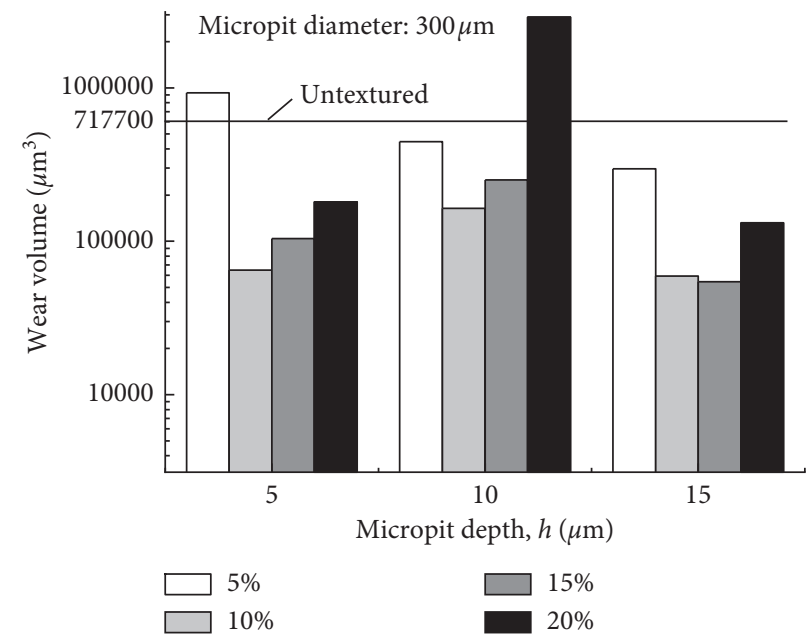

(b)

Figure 7: Relation of micropits' depth and wear volume. The micropit diameters of (a) $100 \mu \mathrm{m}$ and (b) $300 \mu \mathrm{m}$.

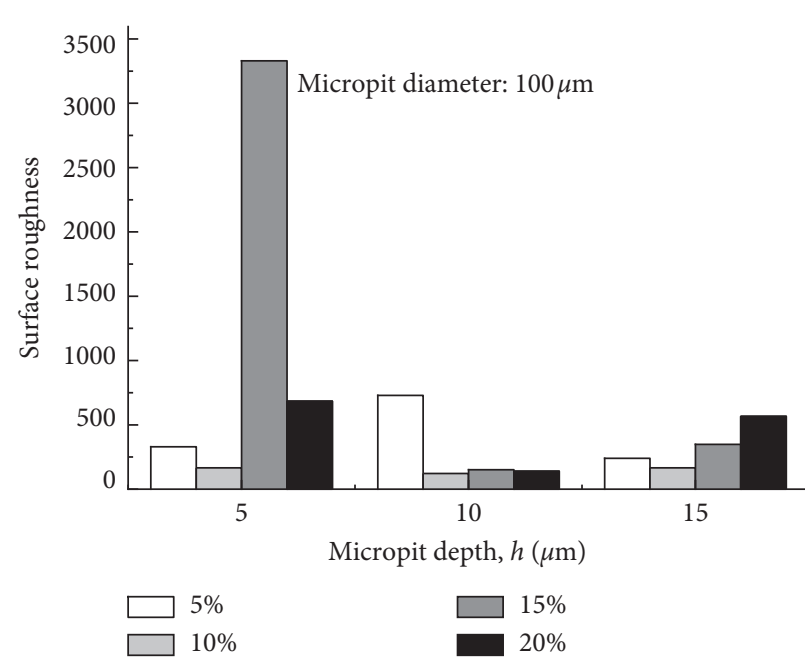

(a)

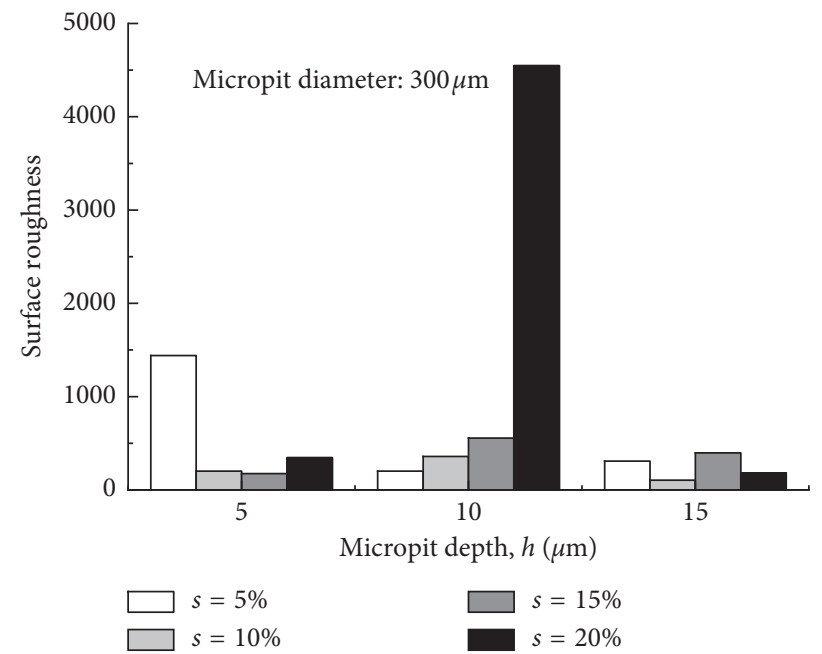

(b)

Figure 8: Relation of surface roughness and micropits' depth. The micropit diameters of (a) $100 \mu \mathrm{m}$ and (b) $300 \mu \mathrm{m}$. 
(1) The effects of the micropit depth on the average wear volume are related to the micropit diameters.

(2) The real micropit depth should be suggestively a bit bigger than the optimal micropit depth in order that the friction pair will still keep good tribology performance when the solid particles are deposited in the micropits or the micropits are worn.

(3) The surface roughness and the wear volume display the similar laws, which can further validate the antiwear effect of the textured port plate pair in the low pressure.

\section{Data Availability}

The data used to support the findings of this study are available from the corresponding author upon request.

\section{Conflicts of Interest}

The authors declare that there are no conflicts of interest regarding the publication of this paper.

\section{Acknowledgments}

This paper was supported by the National Natural Science Foundation of China (Grant no. 51575002) and Open Foundation of the State Key Laboratory of Fluid Power and Mechatronic Systems of China (GZKF-201715).

\section{References}

[1] A. Q. lin, H. Zhou, and H.-Y. Yang, "Development and simulation of lubrication test system for port plate/cylinder block in axial piston pump," Journal of China Coal Society, vol. 29, no. 6, pp. 731-735, 2004.

[2] J. M. Bergada, S. Kumar, D. L. Davies, and J. Wattonb, “A complete analysis of axial piston pump leakage and output flow ripples," Applied Mathematical Modelling, vol. 36, no. 4, pp. 1731-1751, 2012.

[3] R. Shao, L. I. N. Yu-yang, and P.-j. Zuo, "Influencing factors of iron-based powder metallurgy thrust plate infiltrating copper quality," Metal Materials and Metallurgy Engineering, vol. 37, no. 4, pp. 12-14, 2009.

[4] S. Y. Lee, B. S. Kim, S. D. Kim, G. S. Kim, and Y. S. Hong, "Effect of Si doping on the wear properties of $\mathrm{CrN}$ coatings synthesized by unbalanced magnetron sputtering," Thin solid films, vol. 506, pp. 192-196, 2006.

[5] Y. S. Hong and S. Y. Lee, "A comparative study of Cr-X-N (X $=\mathrm{Zr}, \mathrm{Si}$ ) coatings for the improvement of the low-speed torque efficiency of a hydraulic piston pump," Metals and Materials International, vol. 14, no. 1, pp. 33-40, 2008.

[6] Y. Zhou, S. Luo, and S. Liu, "The applied research of $25 \mathrm{Cr} 3 \mathrm{MoA}$ modified by $N$ Ion implantation in the valve plate of pump," Journal of Guizhou University of Technology, vol. 27, no. 5, pp. 50-54, 1998.

[7] D. I. Jiang and H. Zhou, "Pressure and flow characteristic modeling of water hydraulic axial piston pump based on variable fluid properties," Journal of China Coal Society, vol. 38, no. 1, pp. 171-176, 2013.

[8] J. M. Bergada, D. L. Davies, S. Kumar, and J. Watton, "the effect of oil pressure and temperature on barrel film thickness and barrel dynamics of an axial piston pump," Meccanica, vol. 47, no. 3, pp. 639-654, 2012.

[9] J. Ki Kim and J. Y. Jung, "Measurement of fluid film thickness on the valve plate in oil hydraulic axial piston pumps (I)bearing pad effects," KSME International Journal, vol. 17, no. 2, pp. 246-253, 2003.

[10] S. Ye, J. Zhang, B. Xu et al., "Experimental and numerical studies on erosion damage in damping holes on the valve plate of an axial piston pump," Journal of Mechanical Science and Technology, vol. 31, no. 9, pp. 4285-4295, 2017.

[11] J. Zhang, S. Xia, S. Ye et al., "Experimental investigation on the noise reduction of an axial piston pump using free-layer damping material treatment," Applied Acoustics, vol. 139, no. 10, pp. 1-7, 2018.

[12] H. Deng, S. Qi, H. Yu et al., "Numerical analysis for textured port plate of axial piston pump," Transactions of the Chinese Society for Agricultural Machinery, vol. 42, no. 6, pp. 203-207, 2011.

[13] L. Shi, Y. Fang, Q. Dai et al., "Surface texturing on SiC by multiphase jet machining with microdiamond abrasives," Materials and Manufacturing Processes, vol. 33, no. 13, pp. 1415-1421, 2017.

[14] B. Su, L. Huang, W. Huang, and X. Wang, "The load carrying capacity of textured sliding bearings with elastic deformation," Tribology International, vol. 109, pp. 86-96, 2017.

[15] X. Mei, T. Tao, and W. Deng, "The Effects of surface dent depth on the micro-elastohydro dynamic lubrication," Journalof Xi"An Jiaotong University, vol. 31, no. 7, pp. 29-34, 1997.

[16] Y. Qi, Q. Chang, and Z. Shen, "The influence of surface texture depth on the load bearing capacity of oil film," Lubrication Engineering, vol. 37, no. 5, pp. 39-42, 2012.

[17] Z. Han, J. Wang, and D. Chen, "The friction-reduce effect with different depth of concave on the oil-lack lubrication," $L u$ brication Engineering, vol. 32, no. 3, pp. 18-20, 2007.

[18] H. Yu, X. Wang, Z. Sun et al., "Theoretical analysis on hydrodynamic lubrication of cylinder micro-dimple surface texture," Journal of Nanjing University of Aeronautics and Astronautics, vol. 42, no. 2, pp. 209-213, 2010.

[19] H. Liu and Y. Meng, "Hydrodynamic lubrication analysis of textured surfaces with the domain decomposition methodeffect of texture distribution patterns," Tribology International, vol. 27, no. 6, pp. 555-560, 2007. 


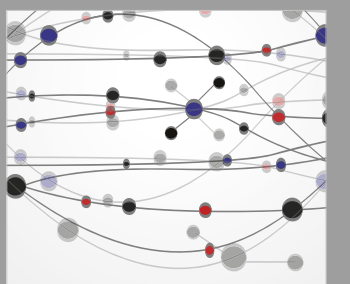

The Scientific World Journal
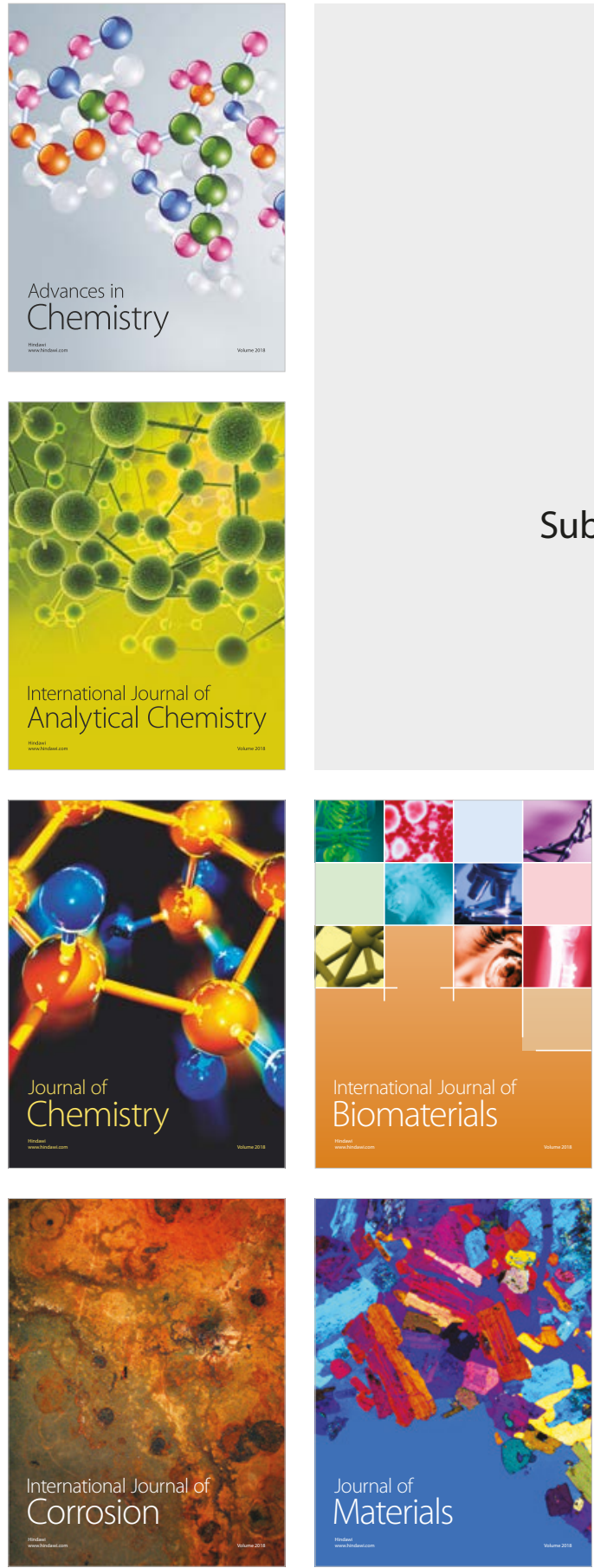

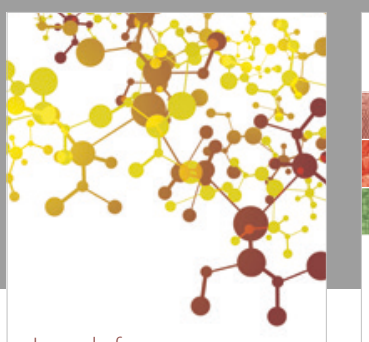

Journal of

Applied Chemistry
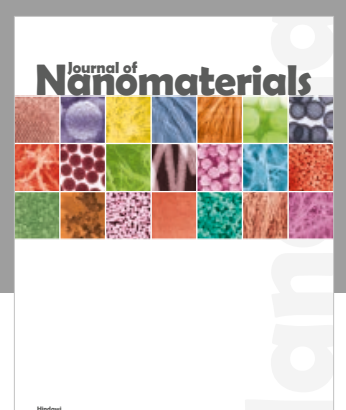

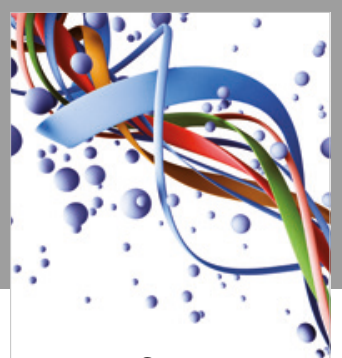

Scientifica

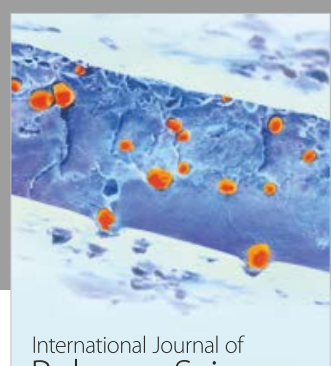

Polymer Science

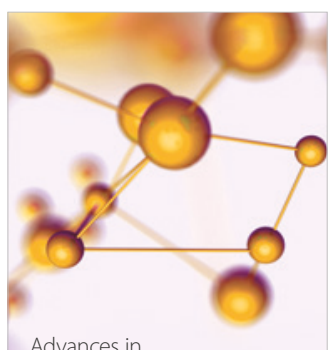

Physical Chemistry
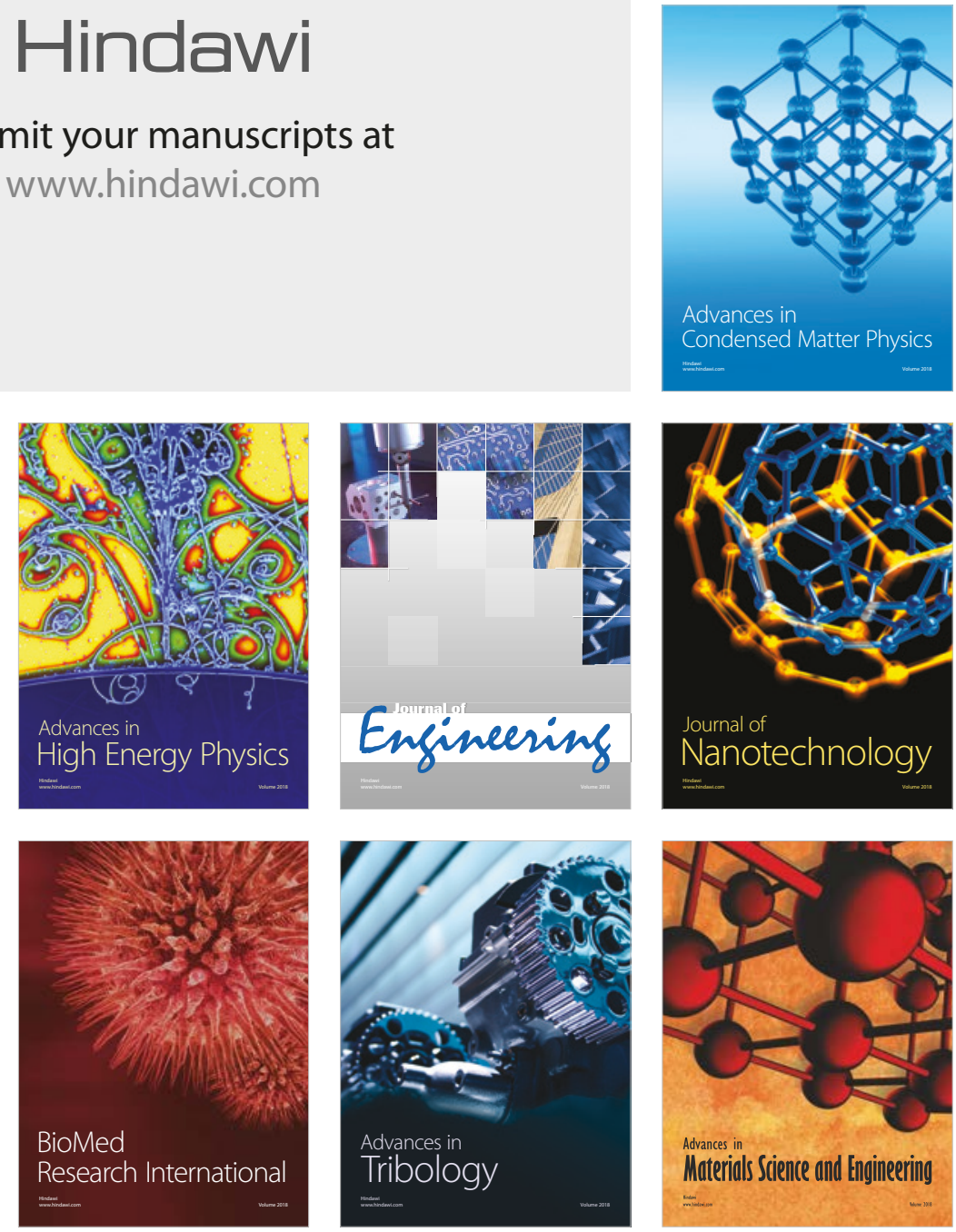